\title{
Correction to: Accountability in Intervention Research: Developing a Fidelity Checklist of a Mental Health Intervention in Prisons
}

\author{
Ashley Givens ${ }^{1}$ (1) $\cdot$ Annie Maria Francis ${ }^{2} \cdot$ Amy Blank Wilson $^{2} \cdot$ Anna Parisi $^{2} \cdot$ Jonathan Phillips $^{2} \cdot$ Melissa Villodas $^{2}$
}

Published online: 2 March 2021

(c) Springer Science+Business Media, LLC, part of Springer Nature 2021

\section{Correction to: Community Mental Health Journal https://doi.org/10.1007/s10597-021-00777-x}

The original version of this article unfortunately contains an error in Ethical approval section.

The last sentence of this section should read as "Informed consent was obtained from all study participants. The data used in this analysis does not include information collected from or about participants in this research study."

The complete updated section is given here:

Ethical approval All procedures and data collection for this study were reviewed and approved by the Institutional Review Board at the University of North Carolina-Chapel Hill. These procedures were performed in line with the tenets of the Declaration of Helsinki. Informed consent was obtained from all study participants. The data used in this analysis does not include information collected from or about participants in this research study.

The original article has been corrected.

Publisher's Note Springer Nature remains neutral with regard to jurisdictional claims in published maps and institutional affiliations.

The original article can be found online at https://doi.org/10.1007/ s10597-021-00777-x.

Amy Blank Wilson

amyblank@email.unc.edu

1 School of Social Work, University of Missouri-Columbia, Columbia, MO, USA

2 School of Social Work, University of North Carolina-Chapel Hill, Chapel Hill, NC, USA 